\title{
INFLUENCE OF REACTION TEMPERATURE AND REACTION TIME ON PRODUCT FROM HYDROTHERMAL TREATMENT OF BIOMASS RESIDUE
}

\author{
${ }^{1}$ Jakaphong Kongpanya, ${ }^{1}$ Kanokorn Hussaro and ${ }^{2}$ Sombat Teekasap \\ ${ }^{1}$ Rattanakosin College for Sustainable Energy and Environment, \\ Rajamangala University of Technology Rattanakosin, PuthamonthonSai 5, \\ Salaya, Puthamonthon, NakhonPathom, 73170, Thailand \\ ${ }^{2}$ Department of Mechanical Engineering, Faculty of Engineering, \\ Eastern Asia University, Thanyaburi, PathumThani, 12110, Thailand
}

Received 2014-04-22; Revised 2014-04-24; Accepted 2014-06-02

\begin{abstract}
Thailand is facing with problems associated with biomass residue such as palm oil residues (oil palm trunks, oil palm fronds, empty fruit bunches, shells and fibers). Biomass is promising source for the production of an array of energy-related produts including, liquid, solid and gaseous fuels, heat, chemicals electricity and other materials. Therefore, the use of biomass for energy is not still fully utilization due to the high moisture content, lower heating value of the energy unit or low bulk density and the problems withtar. While Thailand has high potential because the reisa lot of biomass that has not been utilizedfor example biomass residues from palm oil industry. About 2 million tons of empty fruit bunches in Thailand have great potential. This amount will continue increase with the rapid growth in the Thailand, the largest crude palm oil producer in the world. This amount will continue increase with the rapid growth in the Thailand palm oil industry. Therefore, a better method to manage such biomass residues is highly desired. One of the potential ways for alternative utilization of biomass is thermo-chemical process. Hydrothermal treatment is a process for making a homogenizinged, carbon rich and energy-dense solid fuel, called hydrochar. The objective of the study was to identify the effect of reaction temperature and reaction time for hydrothermal treatment of Empty Fruit Bunches (EFB). Influence of temperature $100^{\circ} \mathrm{C}, 150^{\circ} \mathrm{C}$ and $200^{\circ} \mathrm{C}$ for 30 to $90 \mathrm{~min}$ ) and active biogas process on 1.00-15.538 bars, within 1,000 mL stainless steel 316 batch-type reactor with a stirrer and there is an automatic temperature controller. Results showed that the highest chemical and physical properties of hydrochar product was achieved when operated on $200^{\circ} \mathrm{C}$ for $90 \mathrm{~min}$. Maximum heating value was found that $5678 \mathrm{cal} / \mathrm{g}$ for EFB9. The result showed that the chemical and physical properties increased progressively with higher temperature. The results was indicated that hydro char product of $200^{\circ} \mathrm{C}$ (EFB3, EFB 6 and EFB9) had higher decomposed hemicellose than other product, there were in the range from 76.28 to $81.41 \%$. While hydrochar product of $200^{\circ} \mathrm{C}$ (EFB3, EFB 6 and EFB9) had increased cellulose about 57.09 to 59.14\%. Both time and temperature influence product characteristics, temperature remains the decisive process parameter. Due to there was decreasing polarity and increasing temperature. It should be noted that a manipulation of the water $\mathrm{pH}$ has a significant impact on the reaction mechanism of cellulose and hemicellulose in water. Therefore, temperature of hydrothermal treatment can be used effectively as an operating strategy to hydrochar production.
\end{abstract}

Keywords: Hydrothermal Treatment, Biochar, Empty Fruit Bunches, Reaction Time, Reaction Temperature, Biomass Residues and Oil Palm

\footnotetext{
Corresponding Author: Kanokorn Hussaro, Rattanakosin College for Sustainable Energy and Environment, Rajamangala University of Technology Rattanakosin, PuthamonthonSai 5, Salaya, Puthamonthon, NakhonPathom, 73170, Thailand
} 


\section{INTRODUCTION}

Oil palm is one of the major economic crops in Thailand. It also generates huge quantity of oil palm biomass including oil palm trunks, oil palm fronds; Empty Fruit Bunches (EFB), shells and fibers as waste from palm oil fruit harvest and oil extraction processing there were made into bio-charcoal. The biocharcoalproves to contain more calorific value compared to that of Fresh Fruit Bunch (FFB) (Nukman et al., 2014). Biomass is mainly derived from the agriculture or forestry sector. Today, various forms of biomass are consumed all over the world for energy generation. Biomass provides a clean, renewable energy source that could dramatically improve the environment, economy and energy security (Sukiran et al., 2009).

At present, there is a continuously increasing interest in the utilization of biomass as a source of clean energy. Biomass is one of the most abundant sources of renewable energy and will be an important part of a more sustainable future energy system. In addition to direct combustion, there is growing attention to conversion of biomass into liquid energy carriers. These conversion methods are divided into biochemical/biotechnical methods and thermo chemical methods such as direct combustion, pyrolysis, gasification and liquefaction (Toor et al., 2011). Bio energy technologies use renewable resources to produce array of energy related products including electricity, liquid, solid and gaseous fuels, heat chemicals and other materials as shown in Fig. 1.

Hydrothermal Treatment (HT), the organic matter in the biomass is thermo chemically decomposed by heating in the absence of oxygen, which it is carried out in the presence of subcritical, liquid water. The advantage of HT is that it can convert wet input material into carbonaceous solids at relatively high yields without the need for an energy intensive drying before or during the process, as HT with the solid product consistently called "hydrochar or Low Tar Biomass solid fuel (LTB)". Besides, HT of biomass has a number of advantages when compared with common biological treatment. It generally takes only hours, instead of the days or months required for biological processes, permitting more compact reactor design. In addition, some feed stocks are toxic and cannot be converted biochemically. The high process temperatures can destroy pathogens and potentially organic contaminants such as pharmaceutically active compounds. Furthermore, useful liquid, gaseous and solid end products can be produced and at the same time contribute to GHG mitigation, order reduction and additional socio-economic benefits. In addition, use as bio char (from dry pyrolysis) may contribute to climate change mitigation and soil amelioration (Libra et al., 2011).

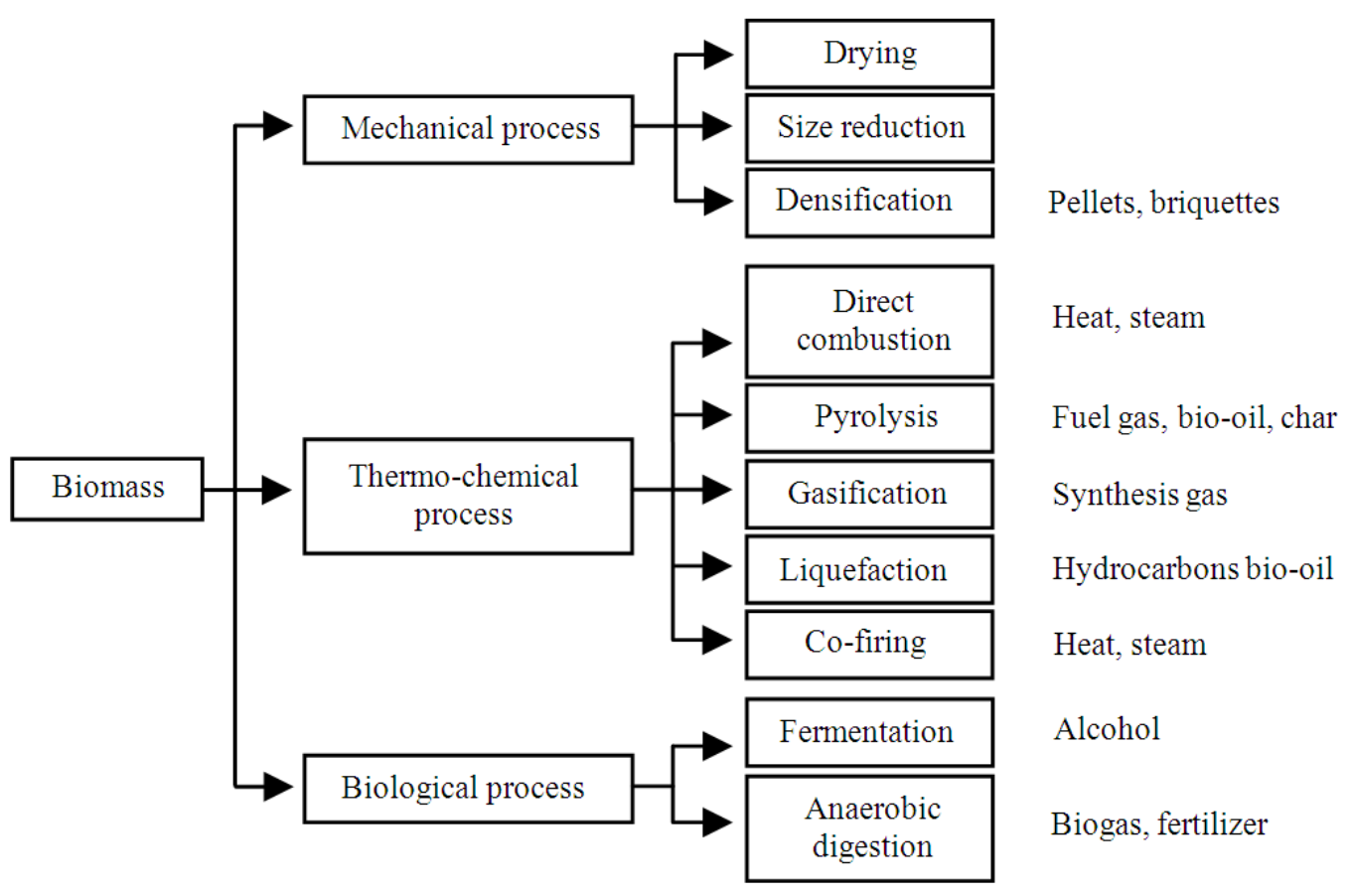

Fig. 1. Pathway for energetic utilization of biomass (Kerdsuwan and Laohalidanond, 2011) 
The hydrothermal technique has received increasing attention because of its potential for efficient biomass conversion. Hydrothermal methods can treats mixtures of biomass and water and convert them directly into gas, liquid and solid products under certain pressure and temperature. Hydrothermal conversion technology can break up organic wastes under oxygen-deficient conditions, producing $\mathrm{CO}_{2}, \mathrm{H}_{2}, \mathrm{CO}, \mathrm{CH}_{4}$. And other gases, oil and char. Hydrothermal process parameter selection directly determines the composition and proportion of the target products, so biomass hydrothermal processes can be divided into hydrothermal carbonation, hydrothermal liquefaction and hydrothermal gasification, depending on the type of the target product (Ying et al., 2011). In the other hand, hydrothermal treatment is one of thermo-chemical process have attracted much attention recently. In this process, biomass is treated in hot compressed water yielding in gases, aqueous organics and upgraded solid. After filtered and dried, the obtained solid can be used for solid fuel due to its high calorific value. Compared to other thermo-chemical conversion methods such as pyrolysis and gasification, the temperature for hydrothermal treatment is much lower
(200-300 ${ }^{\circ} \mathrm{C}$ for hydrothermal, compared with 450$550^{\circ} \mathrm{C}$ for pyrolysis and $900-1200^{\circ} \mathrm{C}$ for gasification, as shown in Fig. 2 (Yuliansyah et al., 2010).

Hydrochar has been considered as a coal substitute in gasification and combustion application and hydrothermal treatment of black liquor would be attractive because: (i) Drying would not be necessary, (ii) deposition or organic alkalies salt in reactor would be inhibited, because alkalies salt should be dissolved in water under hydrothermal condition, (iii) the nitrogen and sulfur oxides formed would be dissolved in the alkaline water solution and further treatment would be unnecessary and (iv) the required temperature would be lower than that required for other thermo-chemical methods (Kang et al., 2012), such as gasification and pyrolysis, as can seen in Fig. 2. In addition, understanding the physical, chemical, thermal and combustion characteristics of hydrochar is important for use of these materials as an energy source (Parshetti et al., 2013). Traditional methods such as composting and incineration are not suitable to process these organic solid wastes, as they contain small concentrations of nitrogen for composting and a considerable amount of solid grains and smoke would be released to pollute the environment during incineration.

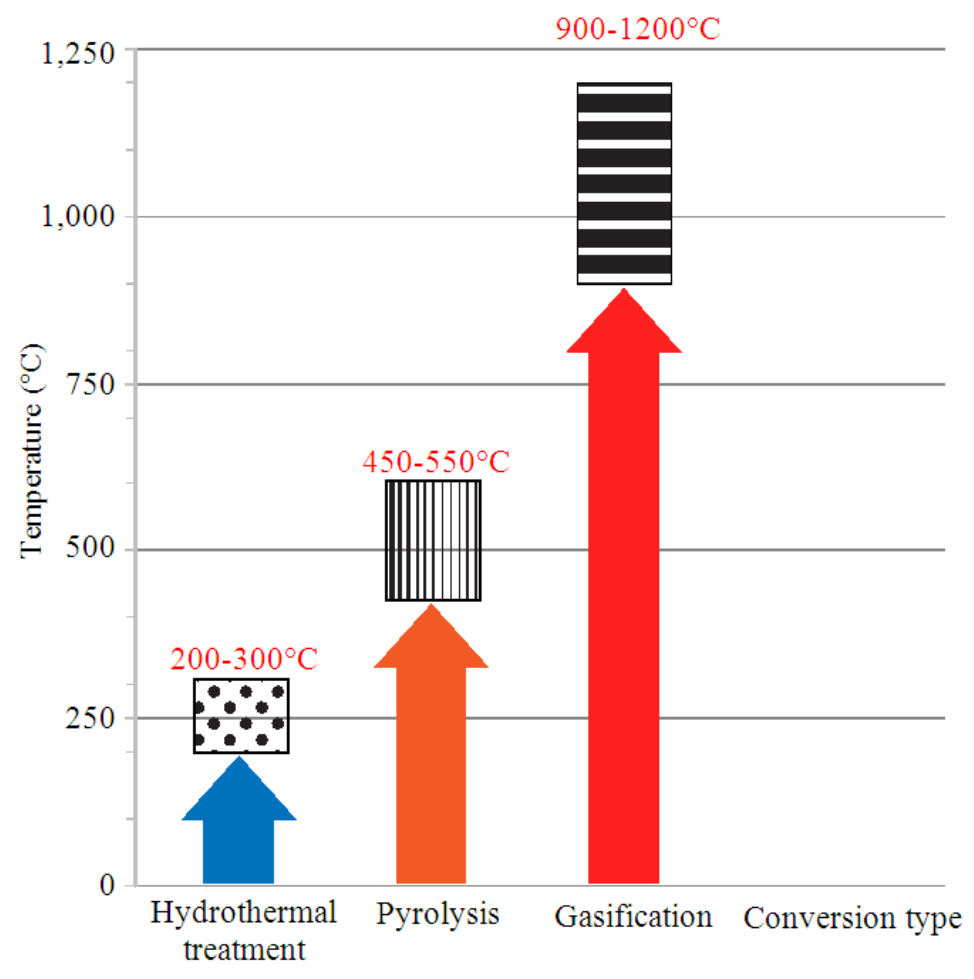

Fig. 2. The temperature condition of different method for convert biomass to energy 
Therefore, a practical method should be to pyrolyse EFB for providing char, EFB vinegar and bio-oil (Khor et al., 2009). About $80 \%$ of the total amount of Empty Fruit Bunches (EFB) produced in Thailand is disposed by landfilling. Moreover, the adverse environmental effects on soil, water and air drawn by unsanitary and unstable landfills are demonstrated. Therefore, in the present research, Empty Fruit Bunches (EFB) was used as a raw material for hydrochar production by hydrothermal treatment.

The aims of the present study were (i) production of hydrochar by hydrothermal treatment using Empty Fruit Bunches (EFB) as a raw material and (ii) to quality the main influencing factors (reaction temperature and retention time) regarding the chemical and physical properties of hydrochar.

\section{MATERIALS AND METHODS}

\subsection{Materials}

The materials used for this research were oil palm residues in the form of Empty Fruit Bunch (EFB). The oil palm residues were collected from a southern Thailand (Suratthani province). It was cutting and milling which introduced into the reactor directly from the bale in lengths ranging from 1 to $5 \mathrm{~mm}$. At the beginning of the experiment, samples of raw material were collected and analyzed for the following parameters: The proximate analysis was conducted according to the ASTM (1996) and the results were expressed in terms of moisture, volatile matter, ash and fixed carbon content. The elemental composition (Ultimate analysis) was measured using a CHNS/O ANALYZER (PE2400 Series II). Analysis of heating value of the dried oil palm residues is performed by a Parr bomb calorimeter. In addition, the cellulose, hemicellulose and lignin contents were measured using a procedure recommended by US National Renewable Energy Laboratory that is substantially similar to ASTM E1758-01, which the results is shown in Table 1.

\subsection{Experimental Method}

Hydrothermal treatment experiments were conducted in a 1,000 mL stainless steel 316 batch-type reactor with a stirrer and there is an automatic temperature controller as shown in Fig. 3 and the experimental set up as shown in Table 2. The reactor was loaded with $30 \mathrm{~g}$ of raw material and $300 \mathrm{~mL}$ of water. The reactor had a maximum temperature $500^{\circ} \mathrm{C}$. A stream of $\mathrm{N}_{2}$ gas was used to purge air from the reactor and to maintain an initial internal pressure of $1.00-15.538$ bars with water cooler system. The target temperature ranged from 100 to $200^{\circ} \mathrm{C}\left(100^{\circ} \mathrm{C}, 150^{\circ} \mathrm{C}\right.$ and $\left.200^{\circ} \mathrm{C}\right)$ at 30 to $90 \mathrm{~min}(30$ $\mathrm{min}, 60$ and $90 \mathrm{~min}$ ) before the reactor was cooled to ambient temperature. The product was placed on a screen in ambient air for pre-drying. Then it was dried in an oven at $110^{\circ} \mathrm{C}$ to yield the final solid product.

\subsection{Analytical Methods}

At the beginning of the experiment, hydrochar product was collected and analyzed for the following parameters: The proximate analysis was conducted according to the ASTM (1996) and the results were expressed in terms of moisture, volatile matter, ash and fixed carbon content. The elemental composition (Ultimate analysis) was measured using a CHNS/O ANALYZER (PE2400 Series II). Analysis of heating value of the dried oil palm Empty Fruit Bunch (EFB) and the bio char product are performed by a Parr bomb calorimeter. In addition, the cellulose, hemicellulose and lignin contents were measured using a procedure recommended by US National Renewable Energy Laboratory that is substantially similar to ASTM E1758-01 (Kim et al., 2012).

Table 1. Proximate and ultimate analysis results of oil palm empty fruit bunch (Raw material)

\begin{tabular}{lr}
\hline Method & \multicolumn{2}{c}{$\begin{array}{c}\text { Raw material } \\
\text { (empty fruit bunch) }\end{array}$} \\
\hline Moisture (\%) & 9.940 \\
Proximate analysis \% (d.b) & 55.900 \\
Volatile matter & 19.990 \\
Fixed carbon & 14.18 \\
Ash & \\
Ultimate analysis (wt.\%) & 45.000 \\
C & 6.400 \\
H & 0.250 \\
N & \\
Composition of biomass (wt.\%) & 42.757 \\
Cellulose & 30.997 \\
Hemicellulose & 25.871 \\
Lignin & $4,325.000$ \\
Heating value (cal/g)
\end{tabular}

Table 2. The experimental set up condition

\begin{tabular}{ll}
\hline Variables & Conditions \\
\hline Raw materials & $\begin{array}{l}\text { Empty Fruit Bunch (EFB) from palm } \\
\text { oil mill } \\
\text { To maintain temperature and pressure } \\
100-200^{\circ} \mathrm{C} / 1.00-15.538 \text { bars } \\
\text { Water cooler system }\end{array}$ \\
$\begin{array}{l}100,150 \text { and } 200^{\circ} \mathrm{C} \\
\text { Temperature }\end{array}$ & $30,60,90 \mathrm{~min}$ \\
Retention time &
\end{tabular}




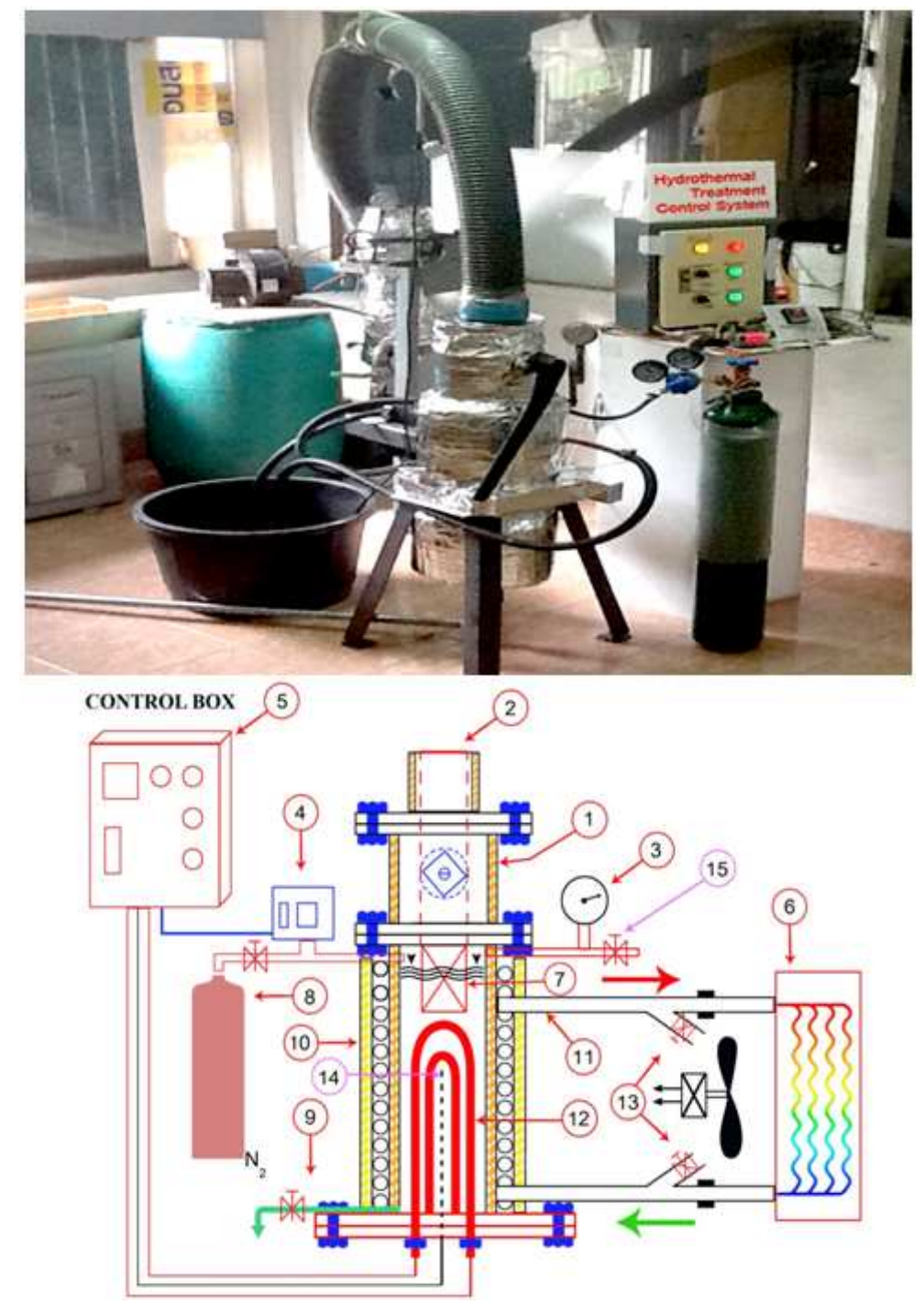

Fig. 3. Schematic diagrams of the experimental apparatus; (1) service valve 1, (2) raw material input/output, (3) pressure gage, (4) pressure control switch, (5) control box , (6) water cooler, (7) reactor, (8) nitrogen cylinder, (9) drain valve, (10) insulator, (11) water input/output, (12) heater, (13) service valve, (14) temperature sensor and (15) safety valve

The characteristics of hydrochar produced by Hydrothermal (HT) were investigated comprehensively to identify the changes of the solid material, especially the carbon component. HT led to thermal degradation of the feed material. Physical and chemical bonds in the material were broken, so that large long-chain compounds such as cellulose, hemicellulose and lignin were broken down into smaller and simpler molecules. Furthermore, some of the molecules were dissolved into liquid part and some others were degraded to gases. The remainder of feed material was recovered as a solid residue. It was placed on a screen in ambient air for pre-drying. Then it was dried in oven at $110-120^{\circ} \mathrm{C}$ for $30 \mathrm{~min}$.

\section{RESULTS}

\subsection{Physical and Chemical Analysis of Hydrochar Product}

The characteristics of hydroochar produced by Hydrothermal (HT) were investigated comprehensively 
to identify the changes of the solid material, especially the carbon component. HT led to thermal degradation of the feed material. Physical and chemical bonds in the material were broken, so that large long-chain compounds such as cellulose, hemicellulose and lignin were broken down into smaller and simpler molecules. Furthermore, some of the molecules were dissolved into liquid part and some others were degraded to gases. The remainder of feed material was recovered as a solid residue. Filtration and drying yielded a solid product from this residue.

The properties of hydrochar (solid products) for different condition are presented in Table 3. Organic compounds represented by percentage carbon of raw material had a significant effect to hydrochar on heating value and chemical composition.

\subsection{Effect of Reaction Temperature and Reaction Time Heating Value of Hydrochar}

For the same reaction temperature (EFB1, EFB4, $\mathrm{EFB} 7$ at $100^{\circ} \mathrm{C}, \mathrm{EFB} 2, \mathrm{EFB} 5, \mathrm{EFB} 8$ at $150^{\circ} \mathrm{C}$ and $\mathrm{EFB} 3$, EFB6, EFB9 at $200^{\circ} \mathrm{C}$ ), hydrochar of Empty Fruit Bunch (EFB) had a higher heating value on $200^{\circ} \mathrm{C}>150^{\circ} \mathrm{C}>100^{\circ} \mathrm{C}$ (as shown in Table 3. While the reaction time (EFB1, EFB2, EFB3 at $30 \mathrm{~min}$, EFB4, EFB5, EFB6 at $60 \mathrm{~min}$ and EFB7, EFB8, EFB9 at 90 $\mathrm{min})$, the above results indicated the highest reaction time in $90 \mathrm{~min}$ results in the highest 5,677.66 $\mathrm{cal} \mathrm{g}^{1}$ at $200^{\circ} \mathrm{C}$ (EFB9). The trends were in close agreement, showing that the heating value in hydrochar with an increase in the reaction temperature (as shown in Fig. 4). The heating value is correlated with the elemental composition of a solid. The data in Table $\mathbf{3}$ show that an increase in heating value is correlated with an increase in carbon content. For the physical color of hydrochar, that there were difference on increasing the reaction and reaction temperature. It is presented on Fig. 5 and 6 show the physical water color of hydrothermal treatment for EFB1-EFB9. HT of biomass can be exothermic reactions. The amount of heat released is dependent on the feedstock used and the reaction parameters, mainly temperature and residence time.

The results of composition analysis of the raw material and hydrochar products are presented Fig. 7. It can be easily concluded, raw material was composed of $42.757 \%$ cellulose, $25.871 \%$ lignin and $30.997 \%$ hemicellulose. About 37.936 and $41.103 \%$ cellulose decomposed, about 23.162 and $25.485 \%$ hemicellulose decomposed at $150^{\circ} \mathrm{C}$ and $200^{\circ} \mathrm{C}$ for $60 \mathrm{~min}$, respectively. However, lignin behavior was different from cellulose and hemicellulose. When hydrothermal treated at $100^{\circ} \mathrm{C}$ to $200^{\circ} \mathrm{C}$, less of lignin decomposed. The results suggest that cellulose and hemicellulose were easier to decompose than lignin.

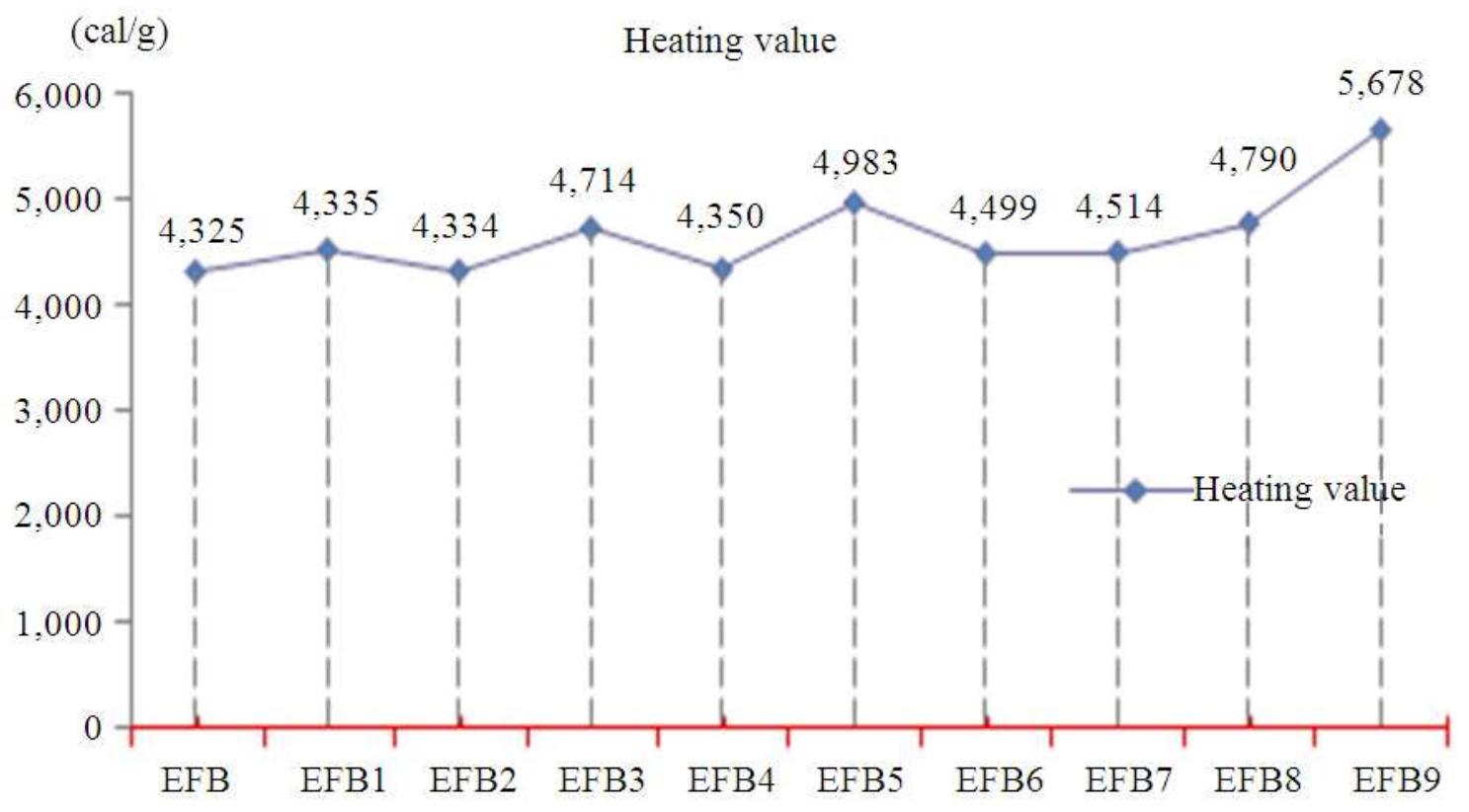

Fig. 4. Heating values of hydrochar products 
Jakaphong Kongpanya et al. / American Journal of Environmental Sciences 10 (4): 324-335, 2014

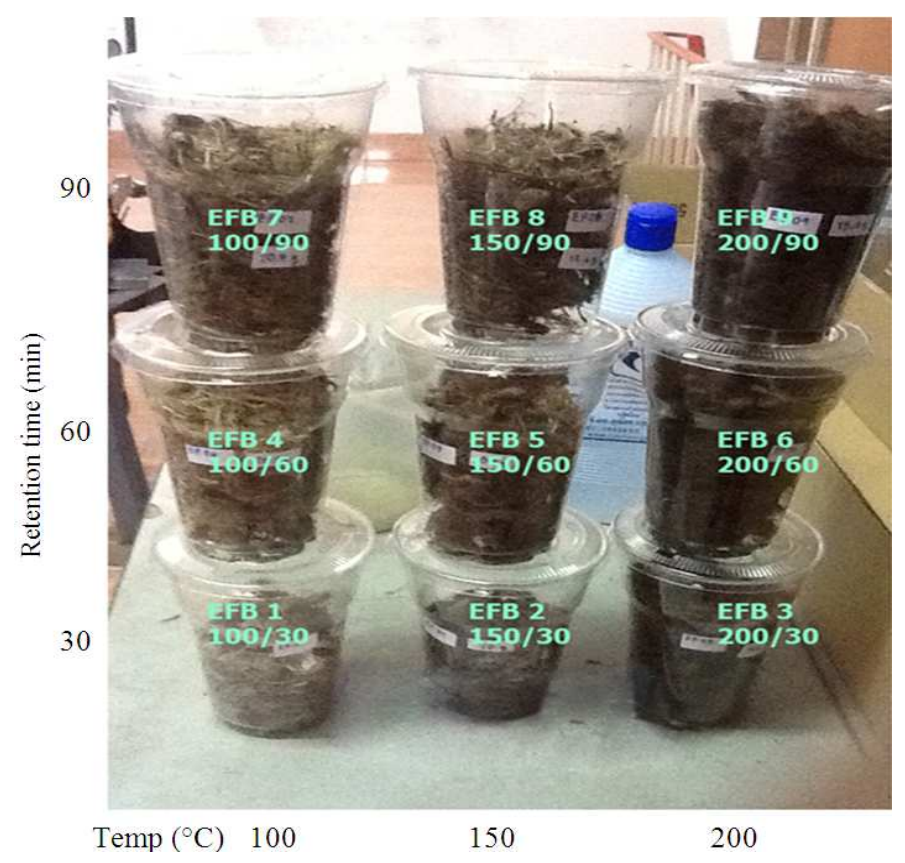

Fig. 5. The physical color of hydrochar product

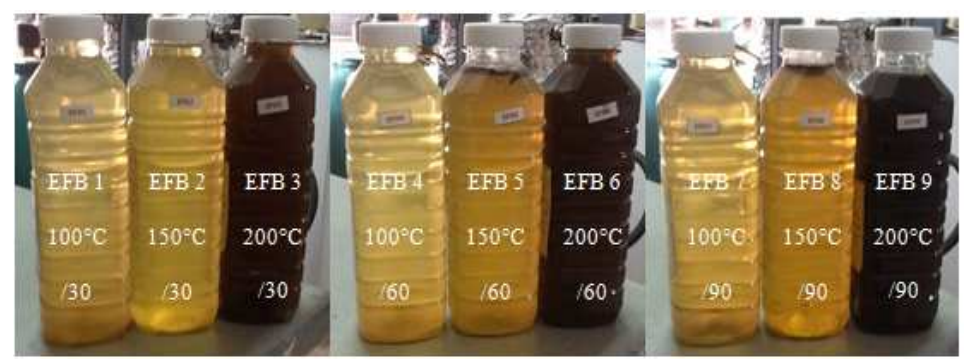

Fig. 6. The physical liquid color of hydrothermal treatment for EFB1-EFB9

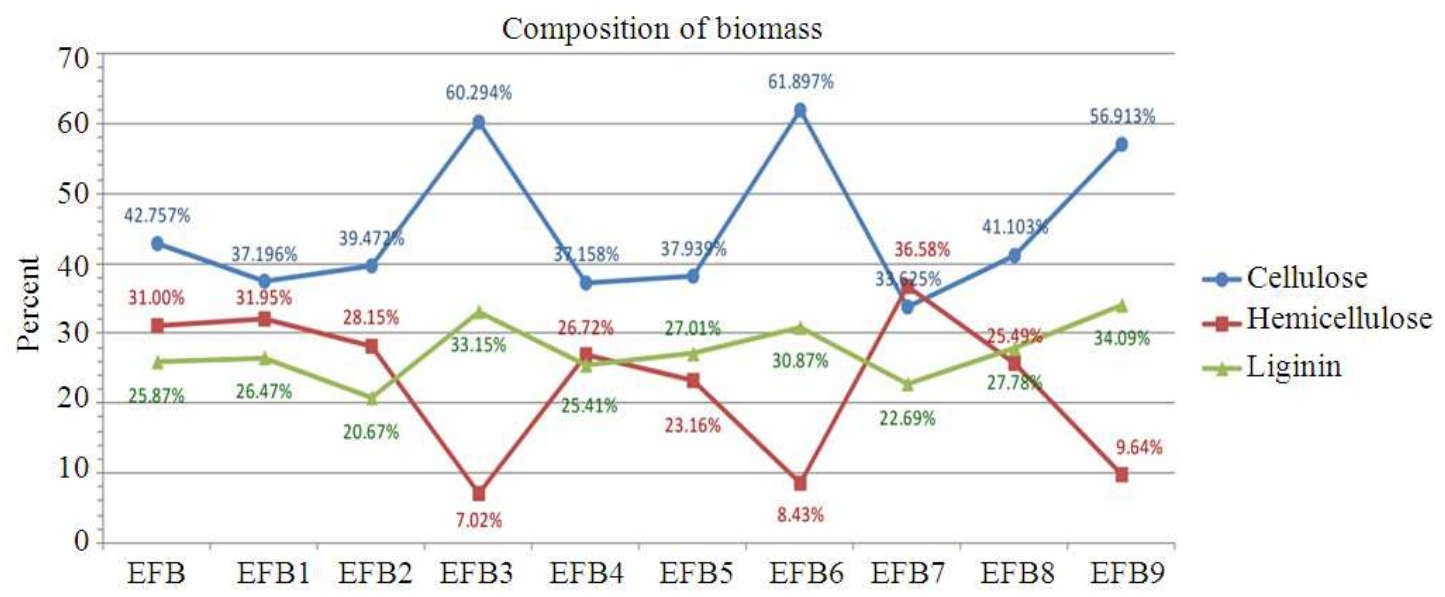

Fig. 7. Characteristics composition of raw material and hydrochar 


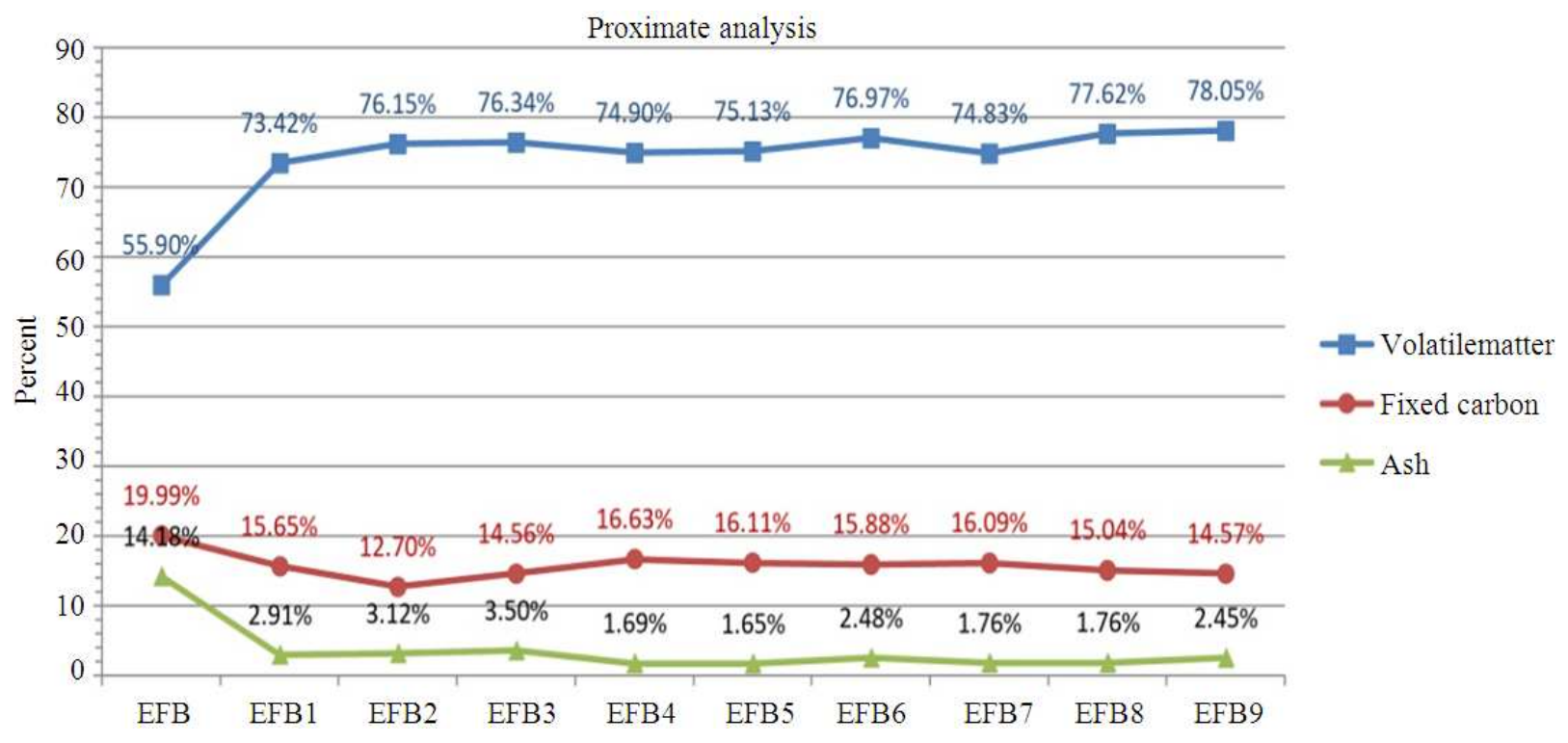

Fig. 8. Ultimate analysis of raw material and hydrochar product

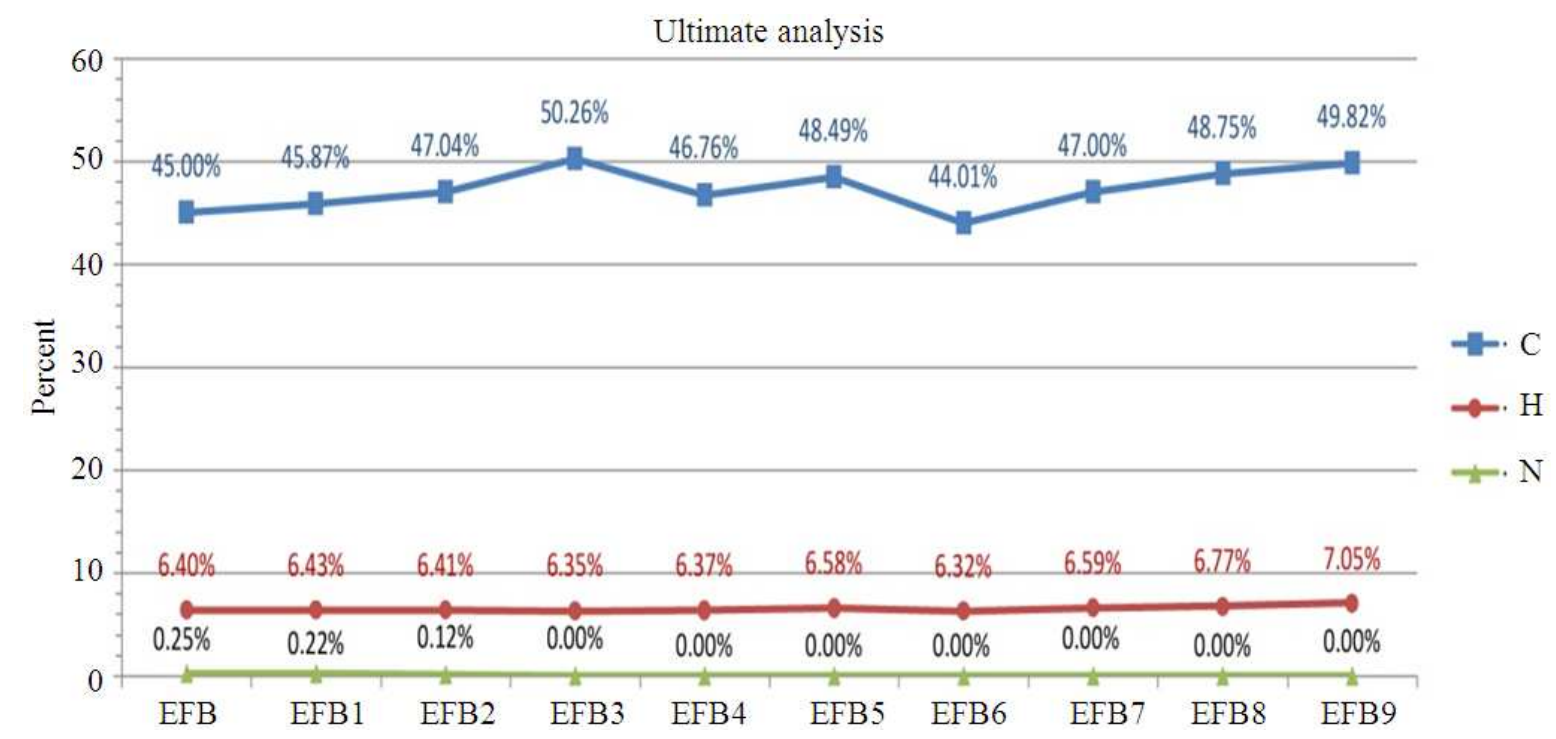

Fig. 9. Proximate analyses of raw material and hydrochar

\subsection{Hydrochar Chemical Characteristics}

The proximate and ultimate analysis of hydrochar at 30-90 min and $100-200^{\circ} \mathrm{C}$ are shown in Fig. 8 and 9. Carbon content resulting from carbonization rage 44.01$50.26 \%$, compared with that of the initial feedstock is $21.15 \%$ and increased with increasing temperature and time of reaction. The chemical properties of raw material were changes by the hydrothermal treatment. With the ash content decreased, which were caused by the hydrolysis reaction. Compare to the raw material, the hydrochar at $200^{\circ} \mathrm{C}$ for 30 amd $90 \mathrm{~min}$ from EFB has $\sim 50.26$ and $50 \%$, respectively, highest carbon content and decrease other content. These results suggest that components degraded and removed from the material were mainly oxygen-rich compounds. 
Table 3. Ultimate and proximate analysis of samples

\begin{tabular}{|c|c|c|c|c|c|c|c|c|c|c|}
\hline \multirow{2}{*}{$\begin{array}{l}\text { Samples } \\
\text { Parameters }\left({ }^{\circ} \mathrm{C} / \mathrm{min}\right)\end{array}$} & EFB & EFB1 & EFB 4 & EFB 7 & EFB 2 & EFB 5 & EFB 8 & EFB 3 & EFB 6 & EFB 9 \\
\hline & Raw material & $100 / 30$ & $100 / 60$ & $100 / 90$ & $150 / 30$ & $150 / 60$ & $150 / 90$ & $200 / 30$ & $200 / 60$ & $200 / 90$ \\
\hline Moisture (\%) & 9.94 & 8.03 & 6.79 & 7.33 & 8.04 & 7.11 & 5.58 & 5.59 & 4.67 & 4.92 \\
\hline \multicolumn{11}{|c|}{ Proximate analysis (\% d.b.) } \\
\hline Volatilematter & 55.90 & 73.42 & 74.90 & 74.83 & 76.15 & 75.13 & 77.62 & 76.34 & 76.97 & 78.05 \\
\hline Fixed carbon & 19.99 & 15.65 & 16.63 & 16.09 & 12.70 & 16.11 & 15.04 & 14.56 & 15.88 & 14.57 \\
\hline Ash & 14.18 & 2.91 & 1.69 & 1.76 & 3.12 & 1.65 & 1.76 & 3.50 & 2.48 & 2.45 \\
\hline \multicolumn{11}{|c|}{ Ultimate analysis ( $\%$ by wt ) } \\
\hline $\mathrm{C}$ & 45.00 & 45.87 & 46.76 & 47.00 & 47.04 & 48.49 & 48.75 & 50.26 & 44.01 & 49.82 \\
\hline$\cdot H$ & 6.40 & 6.43 & 6.37 & 6.59 & 6.41 & 6.58 & 6.77 & 6.35 & 6.32 & 7.05 \\
\hline$\cdot \mathrm{N}$ & 0.25 & 0.22 & 0.00 & 0.00 & 0.12 & 0.00 & 0.00 & 0.00 & 0.00 & 0.00 \\
\hline \multicolumn{11}{|c|}{$\begin{array}{l}\text { Composition of biomass } \\
\text { (\% by wt) }\end{array}$} \\
\hline Cellulose & 42.76 & 37.20 & 37.16 & 33.63 & 39.47 & 37.94 & 41.10 & 60.29 & 61.90 & 56.91 \\
\hline Hemicellulose & 31.00 & 31.95 & 26.72 & 36.58 & 28.15 & 23.16 & 25.49 & 7.02 & 8.43 & 9.64 \\
\hline Lignin & 25.87 & 26.47 & 25.41 & 22.69 & 20.67 & 27.01 & 27.78 & 33.15 & 30.87 & 34.09 \\
\hline Heating value (cal/g) & $4,325.00$ &, 535.00 & $4,350.00$ & $4,514.00$ & $4,334.00$ & $4,983.00$ & $4,790.00$ & $4,741.00$ & $4,499.00$ & $5,678.00$ \\
\hline
\end{tabular}

In addition, Table 3 and Fig. 7 show the content of cellulose, hemicellulose and lignin in the hydrochar at $200^{\circ} \mathrm{C}$ for $90 \mathrm{~min}$. The data suggest that hemicellulose and cellulose were relatively easier to degrade than lignin. The hydrothermal treatment significantly degraded both hemicellulose and cellulose to produce a more ligneous solid. Addition, it was found that, hydrochar from the empty fruit bunch material still had a small amount of hemicellulose. This suggests that hemicellulose decomposition completely $>220^{\circ} \mathrm{C}$. The obtained hydrochar contained a small amount of ash ranging from 1.6504 to $3.504 \mathrm{wt} \%$ (as shown in Table 3). The use of these low-ash products as fuel will be beneficial because it will reduce potential for solid deposition on burner equipment that commonly found on combustion of high ash fuel (Kim et al., 2012). As can be seen, hydrochar from EFB9 had lower ash than other EFB.

\section{DISCUSSION}

A variety of thermochemical or biological processes can be used to convert biomass in the absence of oxygen to products with higher degrees of carbon content than the original biomass. Gas or liquid products (biogas or alcohol0 predominate in biochemical transformations, while solids (charcoal) are the major commercial products of the thermochemical conversion. Hydrothermal processes take place in liquid water at elevated temperatures, that is, the pressure in the system must be at or above saturated pressure. There are classified by different regions above the vapor-pressure curve and the critical point in phase diagram of water, as can seen in Fig. 10. In order to produce a hydrochar (solid product, reaction temperature must be limited in order to avoid gasification and liquefaction (Kruse et al., 2013). The researches indicate that different reaction temperature and different reaction time produce different conditions. In this results, examined the hydrochar by hydrothermal treatment of EFB at 100 to $200^{\circ} \mathrm{C}$ for 30 to $90 \mathrm{~min}$.

In this result, it was found that carbon content was increasing with increased in reaction temperature. Hydrochar (EFB9, hydrothermal treatment at $200^{\circ} \mathrm{C}$ for $90 \mathrm{~min}$ ) had highest carbon content, which was $50 \%$ proximately. In this reason, water at high temperatures becomes a good solvent for hydrocarbons that are typically nonpolar hydrophobic under standard environmental condition. The effect of temperature on water molecules dissociation initial constant at $200^{\circ} \mathrm{C}$ is about times higher than that of $25^{\circ} \mathrm{C}$ atmospheric pressure.

The increase in dissociation constant will increase the rate of both acid and base-catalyzed reactions in water far beyond the natural acceleration due to increased temperature (Zhang, 2010). According to in additional, the highest temperature reached during the process has a critical influence on pyrolytic reactions and the properties of the hydrochar product.The results was indicated that hydrochar product of $200^{\circ} \mathrm{C}$ (EFB3, EFB 6 and EFB9) had higher decomposed hemicellose than other product, there were in the range from 76.28 to $81.41 \%$. While hydrochar product of $200^{\circ} \mathrm{C}$ (EFB3, EFB 6 and EFB9) had increased cellulose about 57.09 to $59.14 \%$. Due to, the principle biomass components are less stable under hydrothermal a condition, which leads to lower decomposition temperatures. 
Jakaphong Kongpanya et al. / American Journal of Environmental Sciences 10 (4): 324-335, 2014

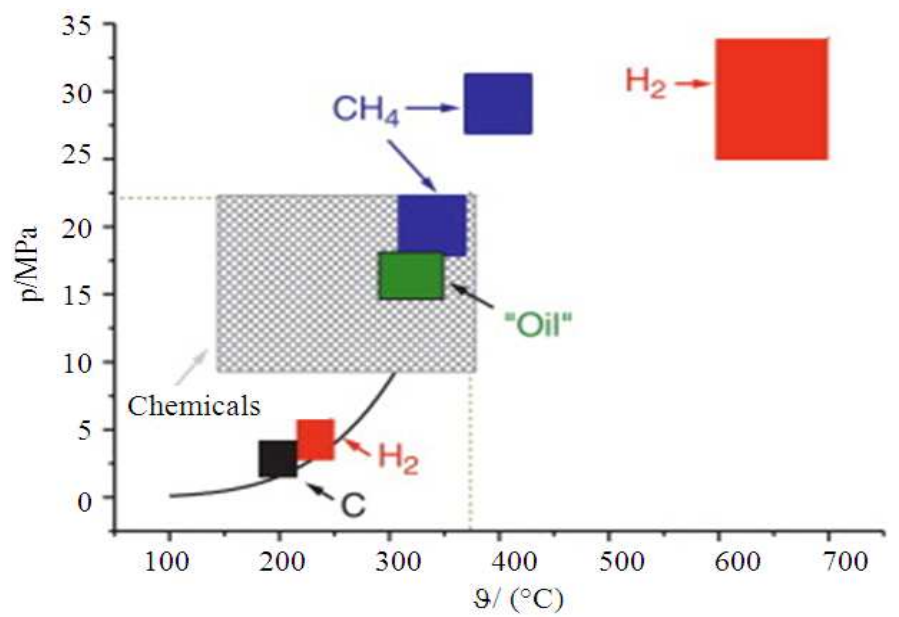

Fig. 10. Typical temperature and pressure ranges in biomass conservation processes (Kruse et al., 2013)

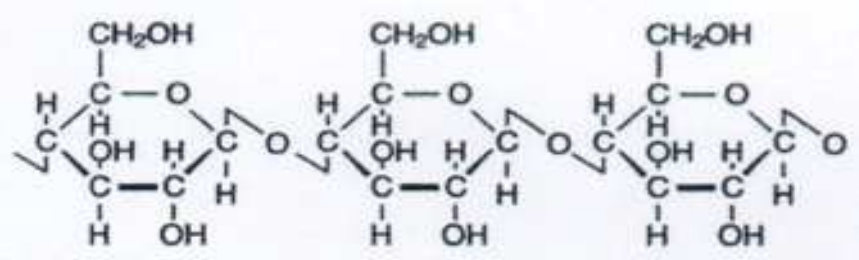

(a)

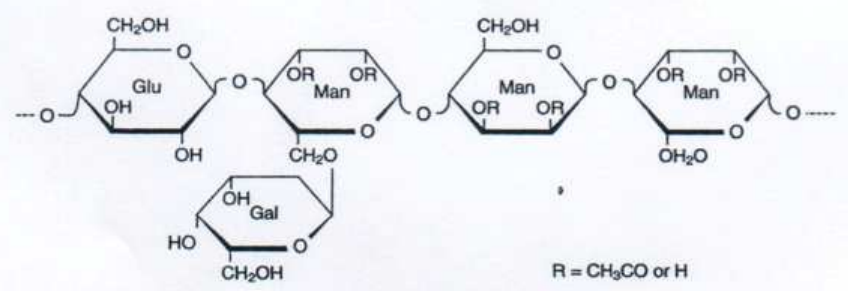

(b)

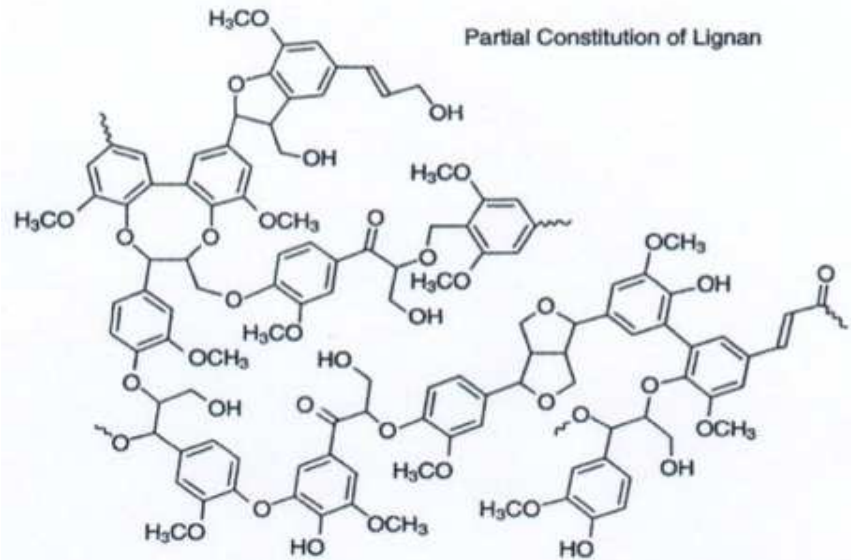

(c)

Fig. 11. Chemical structure of (a) cellulose (b) hemicelluloses and (c) lignin (Zhang, 2010) 
Hemicelluloses decompose 180 to $200^{\circ} \mathrm{C}$ most of the ligninsabove $280^{\circ} \mathrm{C}$ (Zhang, 2010) and cellulose above approximately $220^{\circ} \mathrm{C}$. Although it had been observed that both time and temperature influence product characteristics, temperature remains the decisive process parameter. It should be noted that a manipulation of the water $\mathrm{pH}$ has a significant impact on the reaction mechanism of cellulose and hemicellulose in water (Libra et al., 2011). There were a few changes in lignin content (\%). Due to, the chemical structure of lignin is more complex than cellulose and hemicellulose. It resembles a network of aromatic compounds linked together in a more random fashion (as shown in Fig. 11). Lignin has high carbon content typically more than $60 \%$ and about $30 \%$ oxygen. Although in smaller amounts than cellulose, lignin represents about haft of the available combustible energy in naturally occurring sources (Zhang, 2010). Therefore, the present results in practice suggest that by drochar production by hydrothermal treatment can be optimized if a treatment with highest reaction temperature and reaction time $\left(200^{\circ} \mathrm{C}\right.$ and $\left.90 \mathrm{~min}\right)$, using Empty Fruit Bunches (EFB) as a raw material.

\section{CONCLUSION}

The study showed that chemical and physical properties of Empty Fruit Bunches (EFB) and hydrochar varied as a function of reaction temperature and reaction time, which was operated by hydrothermal treatment at 100 to $200^{\circ} \mathrm{C}$ for 30 to $90 \mathrm{~min}$. The resulted showed that increasing reaction temperature during hydrothermal treatment procedure leads to increasing carbon content. Due to there was decreasing polarity and increasing temperature is associated with deceasing hemicellulose and increasing cellulose. At treatment temperature $200^{\circ} \mathrm{C}$, there were the better of chemical and physical properties of hydrochar product. The dramatic changes in the physical and chemical properties of hydrochar, which there were increased, suggest the possibility of organic chemical reactions to take place. It was become more compatible with the reactions of organics as the temperature is increased.

Compared to the hydrochar product by hydrothermal treatment of palm empty fruit bunches at $150-350^{\circ} \mathrm{C}$ reported by (Parshetti et al., 2013), the results shown that there were investigated comprehensively to identify the change of the solid material, especially the carbon content. The carbon content increased with increasing operating temperature, which was $49.58,54.30$ and $66.02 \%$ for $150^{\circ} \mathrm{C}, 250^{\circ} \mathrm{C}$ and $350^{\circ} \mathrm{C}$, respectively. The other hand,
Kim et al. (2011) reported biomass compositions of hydrothermal product that there were treated at $180^{\circ} \mathrm{C}$, $200^{\circ} \mathrm{C}$ and $220^{\circ} \mathrm{C}$. Solid product had carbon content increased with increasing temperature treatment. About 40 and $60 \%$ cellulose decomposed at $200^{\circ} \mathrm{C}$ and $220^{\circ} \mathrm{C}$. About $90 \%$ and $99 \%$ hemicellulose decomposed at $180^{\circ} \mathrm{C}$ and $220^{\circ} \mathrm{C}$, respectively. However, the lignin behavior was different from hemicellulose. When hydrothermal treated at 180 to $220^{\circ} \mathrm{C}$ less than $5 \%$ of lignin decomposed. The results suggest that hemicellulose was easier to decompose than lignin. However, chemical and physical properties of hydrochar (the carbon content, hemicellulose and lignin) obtained in this research had trend to the literature review (as can seen in Table 2). The hydrothermal treatment is one of the high-temperature and high-pressure water media to upgrade the material in a short time. The limitation of this research, which it is produced hydrochar productto lab-scale. Therefore, the future research should develop to large scale for hydrochar production from other palm oil residues such as oil palm trunks, oil palm fronds and shells and fibers and compared to quality of hydrochar product. Namely suggest that developing the product for using in fuel industrial such as recover to palm oil mill industry for renewable fuel. However, the extra installation costs and efficient of process complexity in hydrothermal treatment system should be evaluated for economic analysis in the next research.

\section{ACKNOWLEDGMENT}

Researchers gratefully acknowledge King's Mongkut University of Technology Thonburi and Technological Research Equipment, Chulalongkorn University.

\section{REFERENCES}

ASTM, 1996. ASTM D3172-Standard practice for proximate analysis of coal and coke. American Society for Testing and Materials.

Kang, S., X. Li, J. Fan and J. Chang, 2012. Solid fuel production by hydrothermal carbonization of black liquor. Bioresource Technol., 110: 715-718. DOI: 10.1016/J.biortech.2012.01.093

Kerdsuwan, S. and K. Laohalidanond, 2011. Renewable Energy from Palm Oil Empty Fruit Bunch. In: Renewable Energy-Trends and Applications, Nayeripour, M. (Ed.), InTech, ISBN-10: 978-953307-939-4, pp: 123-150. 
Khor, K.H., K.O. Lim and Z.A. Zainal, 2009. Characterization of bio-oil: A by-product from slow pyrolysis of oil palm empty fruit bunches. Am. J. Applied Sci., 6: 1647-1652. DOI: 10.3844/ajassp.2009.1647.1652

Kim, D., P. Prawisudha and K. Yoshikawa, 2012. Hydrothermal upgrading of Korean MSW for solid fuel production: Effect of MSW composition. J. Combust., 1: 1-8. DOI: 10.1155/2012/781659

Kruse, A., A. Funke and M.M. Titirici, 2013. Hydrothermal conversion of biomass to fuels and energetic materials. Curent Opin. Chem. Bio., 17: 515-521. DOI: 10.106/j.cbpa. 2013.05.004

Libra, J.A., K.S. Ro, C. Kammann, A. Funke and N.D. Berge et al., 2011. Hydrothermal carbonization of biomass residuals: Acomparative review of the chemistry, processes and applications of wet and dry pyrolysis. Biofuels, 2: 89-124. DOI: 10.4155/bfs. 10.81

Nukman, R.S., I. Yani and T. Arief, 2014. The blending effect of coalite coconut shell charcoal and GELAM wood charcoal on calorific value. Am. J. Applied Sci., $\quad$ 11: $\quad 833-836 . \quad$ DOI: 10.3844/ajassp.2014.833.836

Parshetti, G.K., S.K. Hoekman and R. Balasubramanian, 2013. Chemical, structural and combustion characteristics of carbonaceous products obtained by hydrothermal carbonization of palm empty fruit bunches. Bio. Technol., 135: 683-689. DOI: 10.1016/j.biortech.2012.09.042
Sukiran, M.A., C.M. Chin and N.K.A. Bakar, 2009. Bio-oils from pyrolysis of oil palm empty fruit bunches. Am. J. Applied Sci., 6: 869-875. DOI: 10.3844/ajassp.2009.869.875

Toor, S.S., L. Rosendahl and A. Rudolf, 2011. Hydrothermal liquefaction of biomass: A review of subcritical water technologies. Energy, 36: 2328-2342. DOI: 10.1016/j.energy.2011.03.013

Ying, G., C. Han-ping, W. Jun, S. Tao and W. XianHua et al., 2011. Characterization of products from hydrothermal liquefaction and carbonation of biomass model compounds and real biomass. J. Fuel Chem. Technol., 39: 893-900. DOI: 10.1016/S1872-5813(12)60001-2

Yuliansyah, A.T., T. Hirajima, S. Kumagai and K. Sasaki, 2010. Production of solid biofuel from agricultural wastes of the palm oil industry by hydrothermal treatment. Waste Bio. Valor, 1: 395-405. DOI: 10.1007/s12649-010-9045-3

Zhang, Y., 2010. Hydrothermal Liquefaction to Convert Biomass In to Crude Oil. In: Biofuels from Agricultural Wastes and Byproducts, Hans P., Blaschek, Thaddeus C. Ezeji and Jürgen Scheffran, (Eds.), Blackwell Publising, ISBN-10: 978-0-813-80252-7, pp: 1-10. 